\title{
A randomised, double-blind, placebo- controlled, pilot trial of intravenous plasma purified alpha-1 antitrypsin for SARS-CoV-2- induced Acute Respiratory Distress Syndrome: a structured summary of a study protocol for a randomised, controlled trial
}

Natalie L. McEvoy ${ }^{1}$, Jennifer L. Clarke ${ }^{1}$, Oliver J. Mc Elvaney ${ }^{1}$, Oisin F. Mc Elvaney ${ }^{1}$, Fiona Boland ${ }^{1}$, Deirdre Hyland ${ }^{1}$, Pierce Geoghegan ${ }^{1}$, Karen Donnelly ${ }^{1}$, Oisin Friel', Ailbhe Cullen ${ }^{1}$, Ann M. Collins', Daniel Fraughen ${ }^{1}$, Ignacio Martin-Loeches ${ }^{2}$, Martina Hennessy ${ }^{2}$, John G. Laffey ${ }^{3}$, Noel G. Mc Elvaney ${ }^{1 \dagger}$ and Gerard F. Curley ${ }^{1{ }^{* \dagger}}$ (I)

\begin{abstract}
Objectives: The primary objective is to demonstrate that, in patients with PCR-confirmed SARS-CoV-2 resulting in Acute Respiratory Distress Syndrome (ARDS), administration of $120 \mathrm{mg} / \mathrm{kg}$ of body weight of intravenous Prolastin (plasma-purified alpha-1 antitrypsin) reduces circulating plasma levels of interleukin-6 (IL-6). Secondary objectives are to determine the effects of intravenous Prolastin ${ }^{\oplus}$ on important clinical outcomes including the incidence of adverse events (AEs) and serious adverse events (SAEs).

Trial design: Phase 2, randomised, double-blind, placebo-controlled, pilot trial.

Participants: The study will be conducted in Intensive Care Units in hospitals across Ireland. Patients with a laboratory-confirmed diagnosis of SARS-CoV-2-infection, moderate to severe ARDS (meeting Berlin criteria for a diagnosis of ARDS with a $\mathrm{PaO}_{2} / \mathrm{FiO}_{2}$ ratio $<200 \mathrm{mmHg}$ ), $>18$ years of age and requiring invasive or non-invasive mechanical ventilation. All individuals meeting any of the following exclusion criteria at baseline or during screening will be excluded from study participation: more than 96 hours has elapsed from onset of ARDS; age $<18$ years; known to be pregnant or breastfeeding; participation in a clinical trial of an investigational medicinal product (other than antibiotics or antivirals) within 30 days; major trauma in the prior 5 days; presence of any active (Continued on next page)
\end{abstract}

\footnotetext{
* Correspondence: gercurley@rcsi.com

${ }^{\dagger}$ Noel G. McElvaney and Gerard F. Curley are joint senior authors.

${ }^{1}$ Royal College of Surgeons in Ireland, Dublin, Ireland
}

Full list of author information is available at the end of the article

() The Author(s). 2021 Open Access This article is licensed under a Creative Commons Attribution 4.0 International License, which permits use, sharing, adaptation, distribution and reproduction in any medium or format, as long as you give appropriate credit to the original author(s) and the source, provide a link to the Creative Commons licence, and indicate if changes were made. The images or other third party material in this article are included in the article's Creative Commons licence, unless indicated otherwise in a credit line to the material. If material is not included in the article's Creative Commons licence and your intended use is not permitted by statutory regulation or exceeds the permitted use, you will need to obtain permission directly from the copyright holder. To view a copy of this licence, visit http://creativecommons.org/licenses/by/4.0/. The Creative Commons Public Domain Dedication waiver (http://creativecommons.org/publicdomain/zero/1.0/) applies to the data made available in this article, unless otherwise stated in a credit line to the data. 
(Continued from previous page)

malignancy (other than nonmelanoma skin cancer) which required treatment within the last year; WHO Class III or IV pulmonary hypertension; pulmonary embolism prior to hospital admission within past 3 months; currently receiving extracorporeal life support (ECLS); chronic kidney disease receiving dialysis; severe chronic liver disease with Child-Pugh score > 12; DNAR (Do Not Attempt Resuscitation) order in place; treatment withdrawal imminent within 24 hours; Prisoners; non-English speaking patients or those who do not adequately understand verbal or written information unless an interpreter is available; IgA deficiency.

Intervention and comparator: Intervention: Either a once weekly intravenous infusion of Prolastin ${ }^{\circledR}$ at $120 \mathrm{mg} / \mathrm{kg}$ of body weight for 4 weeks or a single dose of Prolastin ${ }^{\circledR}$ at $120 \mathrm{mg} / \mathrm{kg}$ of body weight intravenously followed by once weekly intravenous infusion of an equal volume of $0.9 \%$ sodium chloride for a further 3 weeks. Comparator (placebo): An equal volume of 0.9\% sodium chloride intravenously once per week for four weeks.

Main outcomes: The primary effectiveness outcome measure is the change in plasma concentration of IL-6 at 7 days as measured by ELISA. Secondary outcomes include: safety and tolerability of Prolastin ${ }^{\circledR}$ in the respective groups (as defined by the number of SAEs and $\mathrm{AEs}$ ); $\mathrm{PaO}_{2} / \mathrm{FiO}_{2}$ ratio; respiratory compliance; sequential organ failure assessment (SOFA) score; mortality; time on ventilator in days; plasma concentration of alpha-1 antitrypsin (AAT) as measured by nephelometry; plasma concentrations of interleukin-1 $\beta$ (IL-1 $\beta$ ), interleukin-8 (IL-8), interleukin10 (IL-10), soluble TNF receptor 1 (sTNFR1, a surrogate marker for TNF-a) as measured by ELISA; development of shock; acute kidney injury; need for renal replacement therapy; clinical relapse, as defined by the need for readmission to the ICU or a marked decline in $\mathrm{PaO}_{2} / \mathrm{FiO}_{2}$ or development of shock or mortality following a period of sustained clinical improvement; secondary bacterial pneumonia as defined by the combination of radiographic findings and sputum/airway secretion microscopy and culture.

Randomisation: Following informed consent/assent patients will be randomised. The randomisation lists will be prepared by the study statistician and given to the unblinded trial personnel. However, the statistician will not be exposed to how the planned treatment will be allocated to the treatment codes. Randomisation will be conducted in a 1:1:1 ratio, stratified by site and age.

Blinding (masking): The investigator, treating physician, other members of the site research team and patients will be blinded to treatment allocation. The clinical trial pharmacy personnel and research nurses will be unblinded to facilitate intervention and placebo preparation. The unblinded individuals will keep the treatment information confidential. The infusion bag will be masked at the time of preparation and will be administered via a masked infusion set to maintain blinding.

Numbers to be randomised (sample size): A total of 36 patients will be recruited and randomised in a 1:1:1 ratio to each of the trial arms.

Trial status: In March 2020, version 1.0 of the trial protocol was submitted to the local research ethics committee (REC), Health Research Consent Declaration Committee (HRCDC) and the Health Products regulatory Authority (HPRA). REC approval was granted on April $1^{\text {st }} 2020$, HPRA approval was granted on April $24^{\text {th }} 2020$ and the HRCDC provided a conditional declaration on April 17 th 2020 . In July 2020 a substantial amendment (version 2.0) was submitted to the REC, HRCDC and HPRA. Protocol changes in this amendment included: the addition of trial sites; extending the duration of the trial to 12 months from 3 months; removal of inclusion criteria requiring the need for vasopressors; amendment of randomisation schedule to stratify by age only and not BMl and sex; correction of grammatical error in relation to infusion duration; to allow for inclusion of subjects who may have been enrolled in a clinical trial involving either antibiotics or anti-virals in the past 30 days; to allow for inclusion of subjects who may be currently enrolled in a clinical trial involving either antibiotics or anti-virals; to remove the need for exclusion based on alpha-1 antitrypsin phenotype; removal of mandatory isoelectric focusing of plasma to confirm $\mathrm{Pi}^{*} \mathrm{MM}$ status at screening; removal of need for mandatory echocardiogram at screening; amendment on procedures around plasma analysis to reflect that this will be conducted at the central site laboratory (as trial is multi-site and no longer single site); wording amended to reflect that interim analysis of cytokine levels taken at 7 days may be conducted. HRCDC approved version 2.0 on September 14th 2020, and HPRA approved on October 22nd 2020. REC approved the substantial amendment on November $23^{\text {rd }}$. In November 2020, version 3.0 of the trial protocol was submitted to the REC and HPRA. The rationale for this amendment was to allow for patients with (Continued on next page) 
(Continued from previous page)

moderate to severe ARDS from SARS-CoV-2 with non-invasive ventilation. HPRA approved this amendment on December 1st 2020 and the REC approved the amendment on December 8th 2020. Patient recruitment commenced in April 2020 and the last patient will be recruited to the trial in April 2021. The last visit of the last patient is anticipated to occur in April 2021. At time of writing, patient recruitment is now complete, however follow-up patient visits and data collection are ongoing.

Trial registration: EudraCT 2020-001391-15 (Registered 31 Mar 2020).

Full protocol: The full protocol (version 3.0 23.11.2020) is attached as an additional file accessible from the Trials website (Additional file 1). In the interest in expediting dissemination of this material, the familiar formatting has been eliminated; this Letter serves as a summary of the key elements of the full protocol.

The study protocol has been reported in accordance with the Standard Protocol Items: Recommendations for Clinical Interventional Trials (SPIRIT) guidelines (Additional file 2).

Keywords: SARS-CoV-2, Covid-19, randomised controlled trial, protocol, Acute Respiratory Distress Syndrome, ARDS, alpha-1 antitrypsin

\section{Supplementary Information}

The online version contains supplementary material available at https://doi. org/10.1186/s13063-021-05254-0.

Additional file 1. Full study protocol.

Additional file 2. SPIRIT 2013 Checklist: Recommended items to address in a clinical trial protocol and related documents*.

\section{Acknowledgements}

Not applicable.

\section{Authors' contributions}

Authors GFC, NGMcE, NLMcE, OJMcE, FB conceptualized the study. All authors made a substantial contribution to the protocol development. All authors read and approved the final manuscript.

\section{Funding}

Grifols provided the investigational medicinal product and funded the cost of trial insurance. Grifols had no role in the design of the study, the collection, analysis or interpretation of data or the preparation of the manuscript.

\section{Availability of data and materials}

The datasets generated and/or analysed during the current study are not publicly available due to relevant data protection laws but may be available from the corresponding author on reasonable request.

\section{Declarations}

Ethics approval and consent to participate

Ethical approval was obtained from the Beaumont Hospital Ethics Committee (Reference \#20-38). Consent or assent was obtained for all participants as appropriate and in accordance with local regulatory frameworks and national legislation.

\section{Consent for publication}

Not applicable.

\section{Competing interests}

The authors declare they have no competing interests.

\section{Author details}

${ }^{1}$ Royal College of Surgeons in Ireland, Dublin, Ireland. ${ }^{2}$ St James' University Hospital, Dublin, Ireland. ${ }^{3}$ Galway University Hospital, Galway, Ireland.
Received: 31 March 2021 Accepted: 7 April 2021

Published online: 19 April 2021

\section{Publisher's Note}

Springer Nature remains neutral with regard to jurisdictional claims in published maps and institutional affiliations.
Ready to submit your research? Choose BMC and benefit from:
- fast, convenient online submission
- thorough peer review by experienced researchers in your field
- rapid publication on acceptance
- support for research data, including large and complex data types
- gold Open Access which fosters wider collaboration and increased citations
- maximum visibility for your research: over 100M website views per year
At BMC, research is always in progress.
Learn more biomedcentral.com/submissions 